\title{
A Plan for a Long-Term, Automated, Broadband Seismic Monitoring Network on the Global Seafloor
}

\author{
Monica D. Kohler ${ }^{* 1}$, Katrin Hafner ${ }^{2}$, Jeffrey Park ${ }^{3}$, Jessica C. E. Irving ${ }^{4}$, Jackie Caplan-Auerbach 5 , John \\ Collins $^{6}$, Jonathan Berger ${ }^{7}$, Anne M. Tréhu ${ }^{8}$, Barbara Romanowicz ${ }^{9}$, and Robert L. Woodward ${ }^{2}$
}

\begin{abstract}
Establishing an extensive and highly durable, long-term, seafloor network of autonomous broadband seismic stations to complement the land-based Global Seismographic Network has been a goal of seismologists for decades. Seismic signals, chiefly the vibrations from earthquakes but also signals generated by storms and other environmental processes, have been processed from land-based seismic stations to build intriguing but incomplete images of the Earth's interior. Seismologists have mapped structures such as tectonic plates and other crustal remnants sinking deep into the mantle to obtain information on their chemical composition and physical state; but resolution of these structures from land stations is not globally uniform. Because the global surface is two-thirds ocean, increasing the number of seismic stations located in the oceans is critical for better resolution of the Earth's interior and tectonic structures. A recommendation for a longterm seafloor seismic station pilot experiment is presented here. The overarching instrumentation goal of a pilot experiment is performance that will lead to the installation of a large number of long-term autonomous ocean-bottom seismic stations. The payoff of a network of stations separated from one another by a few hundred kilometers under the global oceans would be greatly refined resolution of the Earth's interior at all depths. A second prime result would be enriched understanding of large-earthquake rupture processes in both oceanic and continental plates. The experiment would take advantage of newly available technologies such as robotic wave gliders that put an affordable autonomous prototype within reach. These technologies would allow data to be relayed to satellites from seismometers that are deployed on the seafloor with long-lasting, rechargeable batteries. Two regions are presented as promising arenas for such a prototype seafloor seismic station. One site is the central North Atlantic Ocean, and the other high-interest locale is the central South Pacific Ocean.
\end{abstract}

\author{
Cite this article as Kohler, M. D., \\ K. Hafner, J. Park, J. CE. Irving, J. Caplan- \\ Auerbach, J. Collins, J. Berger, A. M. Tréhu, \\ B. Romanowicz, and R. L. Woodward \\ (2020). A Plan for a Long-Term, \\ Automated, Broadband Seismic \\ Monitoring Network on the Global \\ Seafloor, Seismol. Res. Lett. XX, 1-13, \\ doi: 10.1785/0220190123.
}

Supplemental Material

\section{Introduction}

Seismologists are gradually increasing the number of longterm seismic stations operating on continents and islands but have long desired to also instrument the seafloor with them-from shallow continental shelves, across abyssal plains, and in subduction trenches. Such stations are necessary in the oceans to understand the dynamics, composition, and structure of our planet from its shallow crust to its inner core. On land, seismologists have strived for a spacing of no more than a few hundred kilometers between seismic stations.

Long-lived and autonomous seafloor stations far from shore do not exist. High costs and logistics have blocked the way.

\footnotetext{
1. Department of Mechanical and Civil Engineering, California Institute of Technology, Pasadena, California, U.S.A.; 2. Incorporated Research Institutions for Seismology, Washington, D.C., U.S.A.; 3. Department of Geology and Geophysics, Yale University, New Haven, Connecticut, U.S.A.; 4. Department of Geosciences, Princeton University, Princeton, New Jersey, U.S.A.; 5. Geology Department, Western Washington University, Bellingham, Washington, U.S.A.; 6. Woods Hole Oceanographic Institution, Woods Hole, Massachusetts, U.S.A.; 7. Institute of Geophysics and Planetary Physics, Scripps Institution of Oceanography, UC San Diego, La Jolla, California, U.S.A.; 8. College of Earth, Ocean, and Atmospheric Sciences, Oregon State University, Corvallis, Oregon, U.S.A.; 9. Department of Earth and Planetary Science, University of California, Berkeley, Berkeley, California, U.S.A. *Corresponding author: kohler@caltech.edu

(c) Seismological Society of America
} 
Expanding land-based networks of long-term stations into the deep open oceans is nonetheless a widely shared goal. It is a recurring key point of international reports (Purdy and Dziewonski, 1988; Montagner and Lancelot, 1995; Suyehiro et al., 2006), and in reports for the National Science Foundation (NSF) and the U.S. Geoscience Community (e.g., Forsyth et al., 1995). Of the 10 "Grand Challenges" in understanding the Earth's Dynamic Systems (Lay, 2009), seven explicitly demand such seafloor stations to address glaring scientific needs. In the Future Geophysical Facilities Required to Address Grand Challenges in the Earth Sciences (2015) report, the Incorporated Research Institutions for Seismology (IRIS) and UNAVCO communities emphasized the need to expand ocean-bottom seismometer (OBS) and geodetic ability. In the NSF External Review of the Global Seismographic Network (GSN) (2015, p. 28), the review committee reported that "Coverage on the seafloor remains an important expansion of scope, if not imperative. There have been many recent advances in ocean bottom seismometers, and there are developments in underwater robotics that may help reduce marine operation and maintenance costs. A pilot or demonstration is required, possibly with contributions from the Ocean Sciences division in NSF/GEO." Despite these recommendations, progress has been excruciatingly slow. However, the conviction remains: only an integrated, globe-spanning seismic network can capture the body waves, surface waves, and normal modes resulting from multiple large $(\mathbf{M} \sim 7.5+)$ earthquakes needed for resolving crust, mantle, and core structure, and the earthquake rupture details.

In 2017, the IRIS GSN Working Group on Long-Term Seafloor Seismographs (WGLTSS, 2020) was formed to guide the design of seafloor seismic stations to complement the distribution of land stations and to develop a "Pilot Project" to be accomplished during the next 5-10 yr time frame. The authors of this article comprise the WGLTSS.

Feedback from the global seismology community is essential for shaping a seafloor station pilot project, defining the station features and locations, and assuring that the seafloor and land stations complement one another. In the spring of 2018, a survey was distributed to the global seismology community by the IRIS GSN WGLTSS. Respondents were asked to share the outstanding science questions most important to them, in addition to general issues in global seismology that a future seafloor network should address. Additional survey questions sought opinions about instrument design, including sample rate, longevity, and data latency (time lapse between in situ measurement and data delivery to remote scientists and pertinent organizations). In this article, we present the results of this survey, and a recommendation for a pilot project to answer a range of scientific questions. Our intention is that the pilot project should provide results distinct and different from what can currently be accomplished with standard shorter-term deployments of OBSs, either stand-alone or in array configurations.

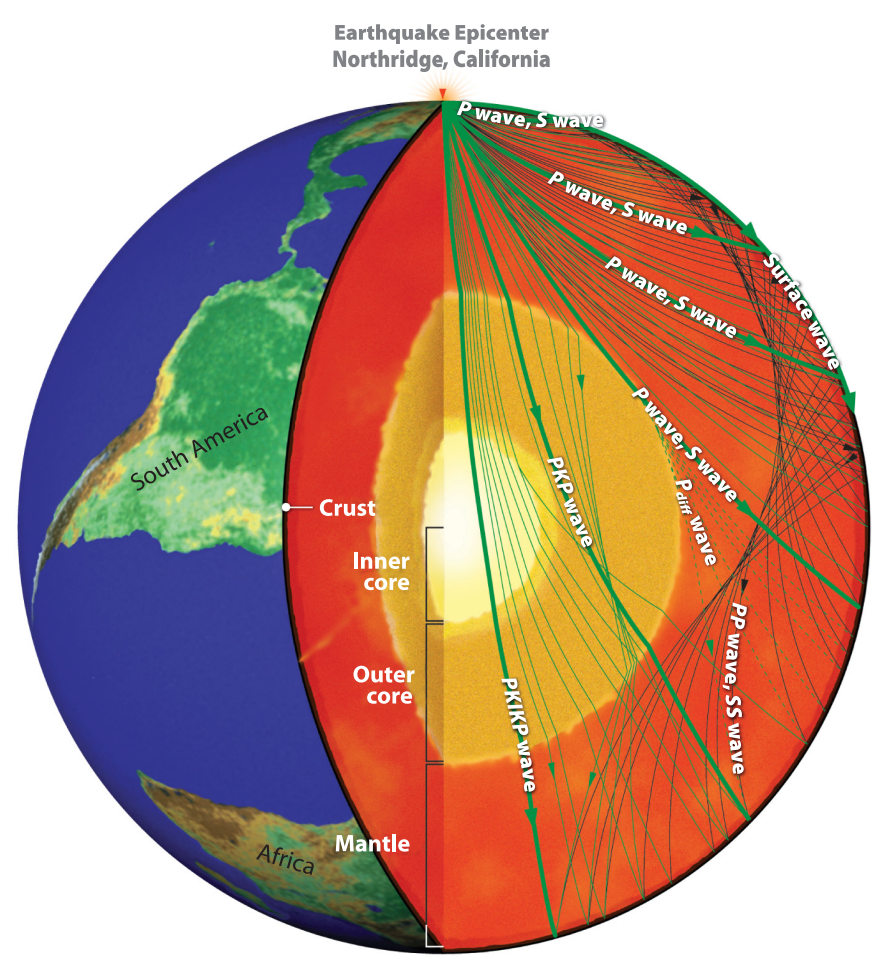

Figure 1. Cutaway of the Earth's interior showing the major components and a selection of seismic phases produced by a hypothetical earthquake whose epicenter is in Northridge, California. Vertical left square brackets indicate the minimum and maximum distances to the inner core (5100-6360 km), outer core (2900-5100 km), mantle (about 50-2900 km), and crust (0 to about $50 \mathrm{~km}$ ). Green rays indicate direct, refracted, or diffracted wave paths, and black rays indicate reflected wave paths (Figure credit: Ellen Kappel). The color version of this figure is available only in the electronic edition.

\section{Scientific Motivation}

Important geological processes and deep physiochemical structures lie beneath large swaths of the Earth's surface where seismic observations are scarce, especially the long-term data collection that would allow numerous large earthquakes from many directions to be recorded. Only with recordings from as much of the Earth's surface as is practical can a rich archive of myriad seismic-wave ray paths be amassed-each ray path being one of the many possible tracks that transmit seismicwave energy from source to seismometer (Fig. 1).

Recording seismic waves that have passed through the Earth allows us to construct images of the Earth's internal structure. These waves travel with a speed and direction that is determined by local temperature, pressure, and the mineralogical composition of rocks within the Earth's interior, as well as by the presence of aqueous fluids or molten material. To first order, the Earth's interior has three major compositional layers (Fig. 1). The Earth's core is composed mostly of iron, forming a sphere that includes an inner core of solid metal, surrounded by an outer core of liquid metal undergoing vigorous thermal 
convection while generating the Earth's magnetic field. The Earth's mantle surrounds the core and is composed of silicate rock with a chemical composition close to that of stony meteorites. The Earth's crust is a thin layer of relatively light silicate rocks surrounding the mantle and is proportionally as thin as the skin of an apple. By careful location of earthquake sources and careful timing of wave arrivals recorded around the globe, researchers have developed smoothed images of seismic velocity variations within the crust, mantle, and core by means of tomography, which is based on principles similar to computerized axial tomography (CAT) scans. However, while CATscans construct images of a living person's bones and organs through exposure to a circular array of well-calibrated and precisely located x-ray sources, the sources in seismic tomography are less spatially diverse than $\mathrm{x}$ rays. We cannot choose the times and locations at which the seismic sources occur, and the path they take depends strongly on the Earth's internal structure. Even in the upper mantle, where ray-path coverage is often best, our tomographic images have lateral resolution only on the order of $1000 \times 1000 \mathrm{~km}$ in most oceanic regions. What we do have reveals variations of $1 \%-3 \%$ in density of material and wavespeed in the deep interior, due presumably to temperature and chemical composition differences. Imaging of heterogeneous lower-mantle seismic structure (e.g., displayed as mapped zones of variations in seismic wave velocity, amplitude, or anisotropy) exists in limited regions.

Earthquake-generated seismic waves travel through all parts of the Earth, providing a means of probing structure throughout the planet. Earthquake waves (Fig. 1) can travel at thousands of kilometers per hour, with pressure $(P)$ body waves almost twice as fast as shear $(S)$ body waves. Surface-wave types, such as Rayleigh and Love waves, are often the largest amplitude seismic waves propagating along the Earth's surface, but they can provide information on structure extending tens to hundreds of kilometers deep. Normal modes, at the lowest frequencies, are global-scale, resonant, standing waves that also provide information about deep structure. Only $P$ waves can transmit through liquids, including the Earth's molten outer core. Seismic waves respond to shallow layering by converting elastic energy between $P$ - and $S$-wave types, $P$ producing $S$ waves and vice versa, at sharp boundaries. A seismic imaging approach called receiver function analysis deconvolves the earthquake source rupture from complex $P$ and $S$ wavetrains to infer the depth and properties of such sharp boundaries deep within the Earth. In all types of seismic imaging, including tomography and receiver functions, the more pathways one has to compare (Fig. 1), the more detail can be inferred. When the higher-frequency seismic-wave observations come from the seafloor, they will require long $(4+\mathrm{yr})$ station deployment durations due to ocean floor noise levels in the microseism band that are generally higher than at land sites.

The study of long-period background seismic noise, sometimes called the Earth's "hum," also benefits from globally distributed seismic stations. Its origin seems primarily to be oceanic waves that couple with the solid Earth and excite seismic free oscillations (e.g., Nishida, 2013). Better observation of these sources would improve study of deep-mantle structure using techniques such as correlating ambient noise between nearby sensors. The necessary abundance of observations of these types of waves can only be provided by a complementary, full-ocean network of stations.

Seafloor observations can provide the necessary geographic distribution of observations to shed light on the Earth's internal dynamics. We know much about these processes, but key questions remain unresolved. It is known that the Earth's mantle convects with velocities in the $10-100 \mathrm{~mm} / \mathrm{yr}$ range, but with a geographic pattern that evolves chaotically as the planet loses internal heat over geologic time. Hot rising mantle rock undergoes partial melting, allowing less-dense magma to rise and to form the Earth's crust. A laminated shell of rock, composed of crust and the mantle left behind from partial melting, is the main component of lithosphere, the stiff "plate" of plate tectonics. Oceanic plates originate at mid-ocean spreading ridges, typically submerged more than $2 \mathrm{~km}$ underwater, along linear rifts where seafloor diverges, splitting apart more or less continuously. Old oceanic plates recycle into the Earth's mantle at subduction zones, such as along the Pacific coastlines of Japan, South America, and Alaska. Subduction zones are the locale for the Earth's largest earthquakes and numerous volcanoes, the latter fed from material shed by the sinking plate. The Earth's largest volcanoes, however, are fed by rising hot mantle rock associated with persistent hot spots within the Earth's interior. Each island within Hawaii, for example, originated as volcanoes fed by partial melt from a rising plume of hot mantle rock that seismic tomography has imaged from deep beneath the islands.

Geoscientists disagree on whether all mantle hot spots originate from plumes, or whether thermal plumes are all deepseated, but researchers have correlated many mantle hot spots geographically with two widespread features in the lower mantle where seismic velocities are anomalously low, coincident with anomalously low mass density. These deep-mantle features are denoted by the acronym LLSVP for "Large Low-Shear-Velocity Province," rising 200-800 km upward from the core-mantle boundary and extending laterally for thousands of kilometers beneath the equatorial Pacific Ocean and Africa. At the edges of the LLSVPs, just above the core-mantle boundary, are smaller "ultra-low-velocity zones" (ULVZs), that may harbor small pockets of molten rock. Hypotheses for what LLSVPs and ULVZs represent are numerous and conflicting, ranging from "piles" of dense lithosphere that sank all the way from the ocean floor to the core-mantle boundary, to the residual silicate sludge left over from the Earth's formation 4.5 billion years ago.

Data from seafloor seismic stations will dramatically enhance the value of existing global seismic networks. For 

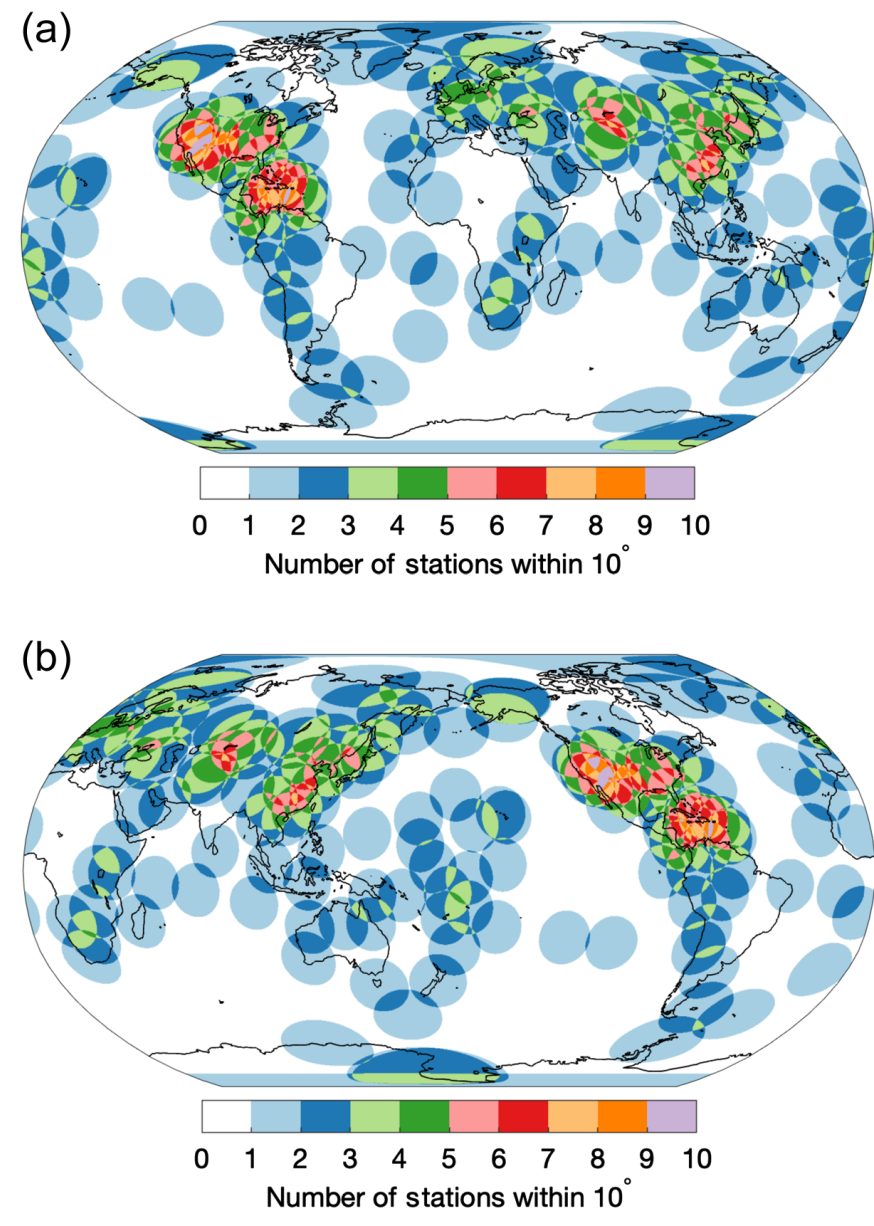

Figure 2. Global Seismographic Network (GSN) station coverage as represented through geographical density of stations.

(a) Africa centered; (b) Pacific centered. Color contours show the number of GSN stations within $10^{\circ}$ of each point on the maps (Figure credit: Andy Frassetto). The color version of this figure is available only in the electronic edition.

example, data from the seismic stations of the GSN on land (Fig. 2) are used in many contexts, from very-long-wavelength normal-mode seismology that has been likened to the Earth gently breathing (e.g., Park et al., 2005; Irving and Deuss, 2011; Pachhai et al., 2016) to urgent seismic hazards including dangerous, oncoming earthquake waves or tsunamis (e.g., Kanamori, 2014). GSN stations are, in many places, sited densely enough for good resolution of deep seismic structure. Several ancient, cooling slabs of oceanic lithosphere have been mapped sinking toward the core, and plumes of material beneath hot spots have been charted as well. But even at the longest wavelengths, large regions of the Earth lack seismic observations. The portions of the Earth's surface that lie directly above the deep-mantle LLSVPs, both in central Africa and the central equatorial Pacific, are poorly sampled by seismic waves; many studies of the LLSVPs use seismic waves that execute extreme reflection paths between widely separated earthquakes and seismometers ( $\mathrm{Yu}$ and Garnero,
2018). Seafloor seismic stations will fill in some of the key observational holes in the GSN, enabling improved imaging of deep Earth structures.

New acquisition geometries that include seafloor stations will have great payoff for understanding the nature of mantle structures such as low-velocity layers and the transition zone between the upper mantle and lower mantle (e.g., Tauzin et al., 2010; Wei and Shearer, 2017; Waszek et al., 2018). In addition, many layers within the Earth exhibit substantial anisotropy, including the lithosphere and upper mantle (e.g., Long and Becker, 2010; Becker and Lebedev, 2019), the lowermost mantle (e.g., Lay, 2015; Romanowicz and Wenk, 2017) where the dominant mineral-slip system in post-perovskite minerals remains uncertain, and in the inner core where anisotropy may be caused by the alignment of individual crystals or larger textures (e.g., Tkalčić, 2015; Romanowicz and Wenk, 2017). In the lowermost mantle, Creasy et al. (2019) demonstrate that having more than one measurement technique and several seismic phases can clarify anisotropy.

Seafloor observations of different composition types and at different frequencies will improve resolution of the deep Earth. Models of inner-core velocity and attenuation are hampered by thin crossing-ray coverage and in some cases by no coverage at all. The inner core clearly shows lateral and radial variations in velocity, anisotropy, and attenuation (e.g., Souriau, 2015). But to understand such heterogeneity requires not just more data but a better conceptual model of the lower mantle. The need for more varied observations can be seen in the coverage of the complex "hemisphere boundary" region in the inner core reported in Yu et al. (2017) who discussed the frustrating paucity of crossing ray paths. This leads to an inherent ambiguity between regional-scale isotropic-wavespeed variations and longer-wavelength anisotropy. Understanding the lateral variation in the inner core is vital for discriminating among the mechanisms proposed for its iron-crystal texture while also accounting for other geophysical properties such as inner-core viscosity (e.g., Tkalčić, 2015).

Stations on the seafloor open the way to sampling regional geology and illuminating geophysical factors pertinent to shallower seismic structure. Most models of oceanic crustal thickness are based on gravity anomalies or on assumed crustal composition rather than on-site data (e.g., Mooney, 2015). Near-surface layering of the crust and upper mantle can be derived from several lines of data. One source is $P$-wave coda, the lingering vibrations that follow the direct $P$ wave and contain scattered waves caused by small-scale seismic heterogeneity. Coda waves persist well after the major phases typically used in tomography. Their existence provides insight into small-scale heterogeneity superimposed on the smooth variations detected by tomography. Other techniques that can reveal crust and upper-mantle structure with seafloor stations include receiver functions to detect sharp shallow boundaries-such as the Moho layer where crust meets 
mantle-and local surface-wave dispersion to resolve shearwave velocities with more detail than global tomography.

Additional seafloor data are crucial for discovering the details of how plate tectonics recycles the Earth's water. Although often narrower than plate boundaries within continents, oceanic boundaries are nonetheless complex. Mid-ocean ridges spread in response to the evolving balance of global plate-driving forces. In the process, they form new tectonic plate material at and under the spreading center. Local chemical interactions with seawater alter the newly forming crust and mantle to depths that currently are poorly constrained. Newly generated "normal" oceanic crust has a typical thickness of 6$9 \mathrm{~km}$ over a wide range of spreading rates. However, crust is much thinner (with thickness approaching near zero) in areas of very slow spreading, including oceanic fracture zones (e.g., Detrick et al., 1993; Grevemeyer et al., 2018). Thick crust (up to $20 \mathrm{~km}$ or more) is seen in areas of abundant magma supply. Typically, such vigorous volcanism occurs on oceanic plateaus, or on or near hot spots (e.g., Dunn, 2015; Van Avendonk et al., 2017).

Temporary OBS deployments have imaged upper-mantle structure along a few sections of the mid-ocean ridge system (e.g., Forsyth et al., 1998; Bodmer et al., 2018), but data paucity limits a convincing general explanation of the underlying dynamics. Temporal trends in global crustal thickness reveal long-term changes in mantle temperature related to plate tectonics and thermal insulation associated with thick stable continents. However, full insight is limited mainly by the scarcity of seismic refraction data sets (e.g., Van Avendonk et al., 2017). For example, seismic structure of oceanic plateaus, such as Ontong Java, are consistent with thickened oceanic crust but not explained easily through simple models of chemical fractionation in which hot mantle rock rises and partially melts (e.g., Korenaga, 2011). Such melting of rising mantle begins about $100 \mathrm{~km}$ below the Earth's surface. Oceanic crustal formation along lengthy spreading centers cycles large volumes of mantle rock through the melting zone. Compositional heterogeneity is generated as some melt migrates and cools to become new crust, and the rest remains part of the underlying residual mantle.

Temporary seismometer arrays, such as leapfrogging shortterm deployments of seafloor arrays (e.g., Pacific Array), floating arrays (e.g., Sukhovich et al., 2015), and other temporary deployments (e.g., Suetsugu and Shiobara, 2014) can provide higher spatial resolution regionally. These are valuable, but typical OBS deployments currently only operate for about 18 months. It takes much longer than this to record enough seismic phases at a single-station location, or from sufficient events in nearly the same source region, to reach adequate signal-to-noise ratios for the full suite of methods that seismologists use to study the Earth's interior. In addition to accumulating many earthquake observations, long-term seafloor observations will record long durations of ambient-noise data that are important for identifying spatial and temporal variations in the sources of the Earth's continuous seismic noise, and to image shallow and deep structure accurately using signals extracted from noise correlations.

On the applied side of the disciplinary spectrum, societal concerns require near-real-time observations (minutes to a few days) from the seafloor (e.g., Kaneda et al., 2015). Disseminating data promptly from stations in oceanic areas will increase accuracy of published earthquake parameters such as location, rupture process, focal mechanism, and moment release (e.g., information from the U.S. Geological Survey National Earthquake Information Center) and would likewise improve tsunami warning systems. Global earthquake catalogs (e.g., Ekström et al., 2012) can become more complete at lower magnitudes but only with data from globally well-distributed stations, with particularly close watch on active plate boundaries. Large data sets flowing from seafloor stations would be critical for both national and international agencies in monitoring and characterizing tsunamis and nuclear explosions. This is especially important for assessing the evolving tsunami risk in real-time warning systems (e.g., Satake, 2015). Furthermore, seismic and hydroacoustic data are used by the United Nations' Comprehensive Nuclear-Test-Ban Treaty Organization to monitor nuclear-test-ban treaty compliance (e.g., Bowers and Selby, 2009).

\section{Development of a Pilot Project Concept: 5-10 Yr Time Frame WGLTSS survey of the global seismology community}

As previously mentioned, the working group distributed a survey in 2018 to gather community input about seafloor seismic station design and received 55 responses to the poll. See Section I in the supplemental material to this article for the survey questions and percentage breakdowns of respondents' answers to each question. Survey responses revealed a strong preference for stations that deliver insight into global-scale seismic structure and provide data to fill gaps or ambiguities in general tectonic regions. Very few respondents preferred a specific seafloor location in the style of temporary, shorter-duration OBS, or portable land array deployments. A few respondents suggested that stations be deployed near a specific class of plate tectonic setting (e.g., a spreading center or hot spot) to illuminate broader tectonic issues. The tenor of responses underscored a preference for recording locations that take best advantage of large-magnitude earthquake location patterns and that have the best chance of capturing specific seismic phases needed to fill glaring data gaps.

\section{Description of pilot project}

We propose a pilot station design here that exploits several recent advances in efficient oceanographic sensing technology. We foresee each "seafloor station" to consist of a dense or small 
aperture array of five individual instrumented units. These units should each include an ocean-bottom broadband seismometer and pressure gauge, coupled with such features as acoustic and optical modems. The stations should be "longterm" in that they can operate with little or no human intervention for at least $4 \mathrm{yr}$, a period that is more than twice the typical operating life of current OBS stations. As described later, sea surface-wave gliders and autonomous underwater vehicles (AUVs) will aid in deployment and servicing. The growth of the seafloor network will reflect the science community's collective priorities through a sequence of subsequent, large-scale deployments.

\section{Pilot project considerations}

Nearly all members of the working group and community participants agreed from the start that a pilot seafloor station should consist of more than one seismometer. Because the harsh seafloor conditions inherently make seismometer access a challenge, and generate high-noise levels in data, redundancy of systems is an intrinsic driver of the design. Discussions focused on configuration (geometric layout and spacing of seismometers) and on the minimum number of individual seismometers (i.e., multiple individual sensors) per station. No particular array configuration needs to be imposed but spacing of sensor units should be concordant with the wavelengths of seismic signals to be analyzed. Tomographic mapping of deep structures will necessarily depend on powerful seismic signals: long-period body waves and surface-wave signals produced by large-magnitude earthquakes. This dictates sensors within 10-30 km of each other. Closer spacing would be required for higher-frequency studies. Stacking (or adding together) data increases signal-to-noise ratio among adjacent sensors. The stations should be designed as little clusters or mini-arrays with at least five (a number that was repeatedly mentioned during discussions) seismometers. Although the stations might have any number of individual seismometer packages, five brings a manageable level of hardware and data redundancy, and ongoing maintenance. Bathymetry constrains the exact final location of each seismometer.

Seafloor stations should be capable of recording all types of seismic waves across a large range of frequencies from about $0.001 \mathrm{~Hz}$ (where oscillation period is $1000 \mathrm{~s}$ or $\sim 17 \mathrm{~min}$ ) to at least $25 \mathrm{~Hz}$ (where oscillation period is $0.04 \mathrm{~s}$ ), and measured along three axes (up/down and two orthogonal horizontal directions). The pilot seafloor station design should, while using new technical advances, deftly coordinate attention to such disparate factors as sensor burial procedure, accurate timing over deployment durations of many years, battery-based power systems able to deliver multiple watts, and continuous telemetry of low-rate $(1 \mathrm{~Hz})$ seismic data from the seafloor to shore. Two-way communications between shore and seafloor station should allow users to get selected segments of high-rate data. All should be deployed with the largest battery pack possible to maximize operational service. Extension of station life without compromising seismometer performance may require replacement of battery packs by remotely operated vehicles. A critical feature is the ability to update software.

\section{Instrumentation and deployment requirements}

OBSs are typically allowed to free-fall from the sea surface to the ocean floor (e.g., Suetsugu and Shiobara, 2014). This provides almost no control over the level and orientation of the installation. At present, most seismometers sit on the seafloor surface rather than beneath the seafloor. Because of this, currents may prevent it from landing flush and coupling well. Even relatively small currents $(\sim 1 \mathrm{~cm} / \mathrm{s})$ can result in instrumental tilt that degrades longer-period (i.e., $>20$ s), horizontal-component data for teleseismic studies. Chance can sometimes work in favor of clean measurements: Bécel et al. (2011) report that a Nanometrics T-240 sensor, deployed on the seafloor via free fall, recorded normal modes at ultralow frequencies $(<1.5 \mathrm{mHz})$. It also recorded the daily tidal motions of the seafloor itself. Vertical-component seismometers are less perturbed by tilt-induced off-axis accelerations. In addition, because ocean floor noise is relatively low at frequencies of $\sim 0.01-0.1 \mathrm{~Hz}$, OBSs can record clear Rayleigh waves and long-period body waves at periods up to at least $70 \mathrm{~s}$ (Laske et al., 2007). Tilting does not affect long-period pressure sensors that also record Rayleigh waves well at similar periods but suffer from noise exacerbated by oceanic infragravity waves at frequencies $<\sim 0.03 \mathrm{~Hz}$. Furthermore, pressure-gauge waveforms can be used to apply compliance and tilt corrections (Webb and Crawford, 1999; Crawford and Webb, 2000) resulting in Rayleigh-wave recordings to periods up to $150 \mathrm{~s}$ (Bell et al., 2016; Lin et al., 2016).

To approach GSN-quality noise performance data, station deployments require burial of the broadband sensor (as opposed to having it sitting on the seabed surface) to screen out much of the long-period noise, particularly on its horizontal components (Collins et al., 2001, 2002; Sutherland et al., 2004; Crawford, 2006; Duennebier and Sutton, 2007). Burial of a seismometer in the shallow seafloor will not significantly reduce short-period noise (Sutherland et al., 2004), but it does improve data quality by enhancing the fidelity of competing ground-motion recordings. Tilt-generated noise is considerably less when the seismometer is buried deep enough to put the top of the seismometer level with the seafloor. Thus deployed, we would expect to record Rayleigh and Love waves clearly out to periods of $100 \mathrm{~s}$. Burial of the seismometer improves not only the surface-wave data but also the quality of receiver function results and measurements of shear-wave splitting parameters (Collins et al., 2002). Noise spectra for buried seismometer station OSN1B in the Ocean Seismic Network Pilot Experiment (Collins et al., 2001) suggest that the quality of long-period data from a buried seismometer is constrained only by inherent seismometer response. The quality of 
horizontal-component data from station OSN1B near Hawaii and from a buried station (MOBB) off the coast of Monterey, California (Dolenc et al., 2005, 2007) was so high that the stations made the first-ever measurements of horizontal seafloor compliance-in this case, the response of the ocean bottom to slight forcing by very-long-wavelength infragravity waves at the surface (Doran and Laske, 2016). On the other hand, short-period, signal-generated noise can be caused by reverberations in the sediments under the seismometer. This shortperiod noise may be unavoidable unless the sensors are installed in bedrock.

\section{Telemetry technologies}

Data-return latency and methods of data delivery generated numerous discussions within the seismological community. Short latency is of urgent importance to seismologists and agencies charged with hazard mitigation, and this community subset assigns high priority to near-immediate data. Satisfying such a demand would weigh heavily on seafloor station design and cost. Most respondents to the WGLTSS survey, however, were less concerned about real-time data transfer due to their areas of interest. Nearly $70 \%$ indicated that latencies of weeks to months are acceptable. Such data could therefore be retrieved via acoustic or optical modem or pop-up data capsules and relayed via satellite. This suggests that the entire system need not be served by fiber-optic cables. Cabled networks are expensive if nodes are far from shore. Hence, a network designed for the deep open ocean could be complemented with cabled stations generally close to land (Monterey Bay Ocean Bottom Seismic Observatory: Romanowicz et al., 2003, 2009; Dense Oceanfloor Network for Earthquakes and Tsunamis: Kaneda et al., 2015, Kawaguchi et al., 2015; Ocean Observatories Initiative's Axial Seamount Cabled array: Kelley et al., 2014; Ocean Networks Canada's Neptune Array: Barnes et al., 2007, Deschamps et al., 2008; Science Monitoring And Reliable Telecommunications cables: Tilmann et al., 2017).

Thanks to recent technological advances, seismic stations with the performance and quality we have specified do not have to rely on cable communication. The foremost example of transformative technology is a Wave Glider (Liquid Robotics, Inc./Boeing), an autonomous maritime vehicle reminiscent of a surfboard that harvests wave and solar energy for electrical power and propulsion. A wave glider has two primary sections - the instrumented float about $3 \mathrm{~m}$ long that rides the surface, and a separate, fully submerged denser-than-water sub or glider beneath it. Between them is a strong, flexible umbilical cable about $8 \mathrm{~m}$ long and containing a data cable. The glider is about two-thirds the length of the float and looks like a flying fish but with a dozen stiff vanes or wings spread laterally. The glider maintains a near-horizontal attitude while its wings pivot on their long axes in a fashion that propels it forward, whether it is rising or sinking through surrounding water.

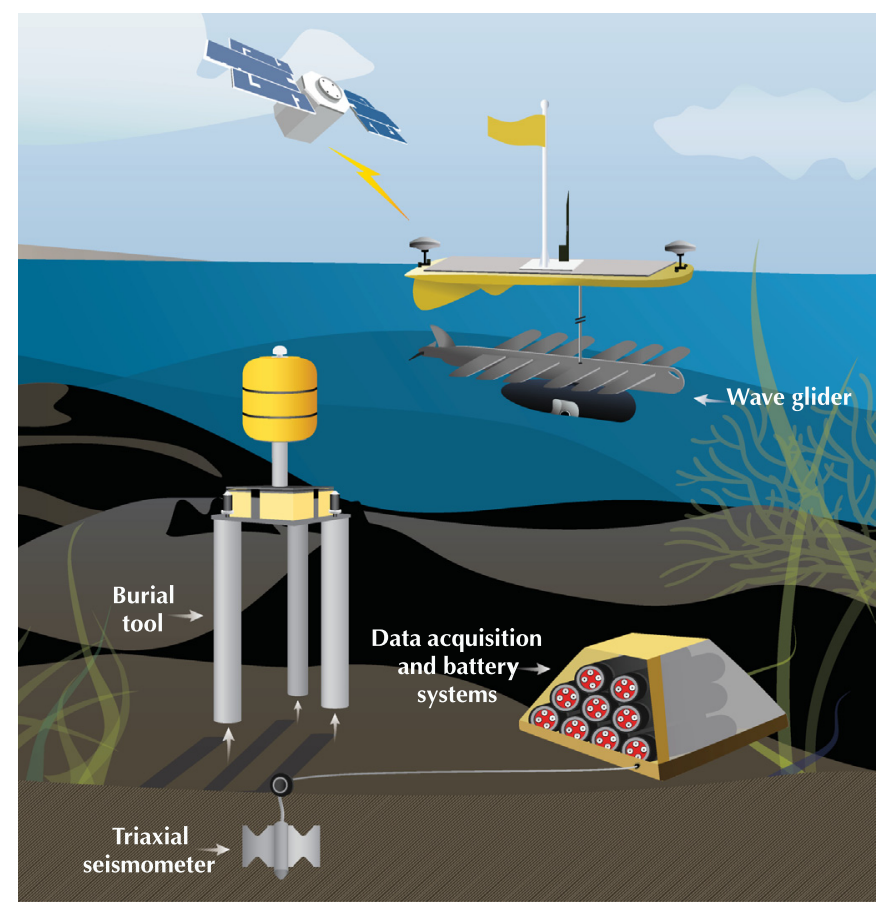

Figure 3. Data offload method involving use of Liquid Robotics wave glider to transmit data via satellite to shore while it holds station over the ocean-bottom seismometer (OBS) using acoustic communication modems. The color version of this figure is available only in the electronic edition.

The glider thus tows the float. The glider-float pair coordinate their control surfaces to keep a common course. In tests in a wide range of sea states, the wave glider's speed averages about $2.4 \mathrm{~km} / \mathrm{hr}$. The devices operate even during hurricanes. The latest versions of the Liquid Robotics autonomous wave glider include on-board sensors and communications systems that make them roving communications gateways sending data from in situ subsea instruments to shoreside data archives via orbiting satellites (Fig. 3).

A wave glider was tested for three months to see how well it could perform while tending a seafloor seismic station $4000 \mathrm{~m}$ deep in the ocean $300 \mathrm{~km}$ west of San Diego, California, just beyond the continental shelf (Berger et al., 2016). To illustrate the machine's autonomy, the wave glider was put in the sea $30 \mathrm{~km}$ offshore. In $261 \mathrm{hr}$, it made its way the remaining $270 \mathrm{~km}$ to its designated post while relying on internal navigation. The wave glider received data by acoustic method streamed from the seafloor. It then transmitted the data to a satellite, for relay to shore, while holding station in a specified pattern above the station.

Near-real-time data can be streamed at $1 \mathrm{~Hz}$ with latency of a few minutes with such a system; higher sample rates are possible upon demand. This level of latency would enable the transmission of data from tsunamigenic earthquakes while the tsunami itself is still unfolding, in time for use in tsunami warning systems. In the offshore San Diego test, the broadband 
(a)

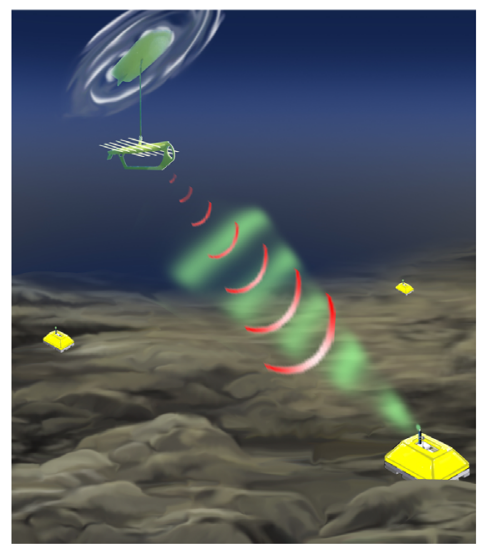

(b)

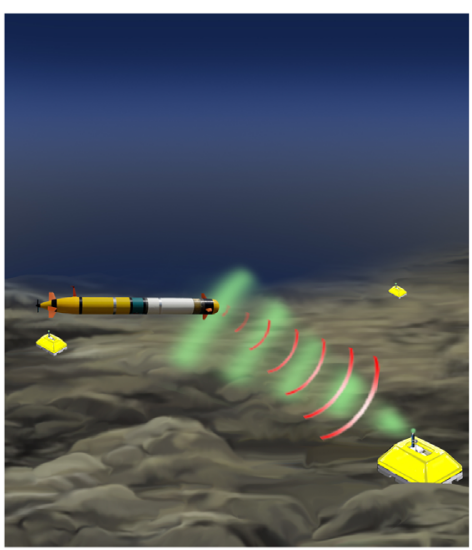

(c)

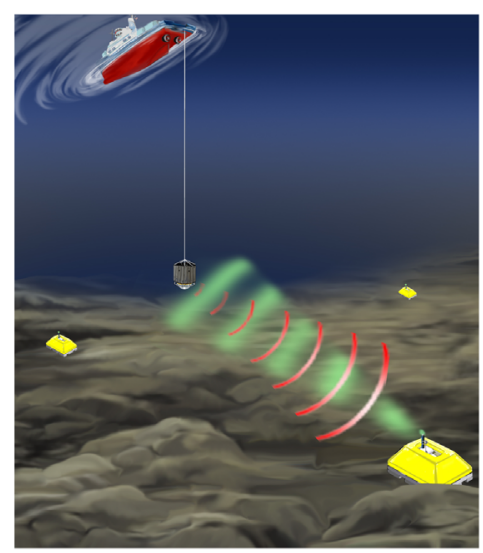

seismometer and pressure gauge (broadband hydrophone) sent data to the sea surface using an acoustic modem that Woods Hole Oceanographic Institution had developed (Fig. 4). The average latency, from seafloor to laboratory on land, was about $4.3 \mathrm{~min}$. Much of the time lag occurred while linking to a satellite for the final communication leg. A similar telemetryfocused OBS experiment took place offshore Vancouver Island (Frye et al., 2006). In that 13-month deployment, continuous low-rate $(1 \mathrm{~Hz})$ seismic and oceanographic data were telemetered acoustically from the seafloor to a moored buoy, and from there to shore via an Iridium satellite link. Shorter, user-specified segments of high-rate seismic data were also telemetered to shore.

The latest model (SV3) wave gliders have an enhanced solar power array and feature a collapsible propeller for maneuvering when waves disappear or currents drive the glider off station. In addition, design advances born from the offshore San Diego, California, test already make practical operation possible for at least $2 \mathrm{yr}$. With sufficient power to download full bandwidth data $(50 \mathrm{~Hz})$, operations can occur for at least 20 days. Wave-glider-enabled ocean surface data gateway systems such as this should drastically reduce the dependence on ship use. They will enhance the delivery of data and information to scientists and any interested users in near-real time. Ship-based connection during the pilot station testing stages would provide the opportunity to refine software for glider-based autonomous vehicles.

Acoustic communication systems have been in use with oceanographic applications and have latencies of milliseconds to seconds. Optical modems are new alternatives to acoustic modems and provide far faster communication from the seafloor to a surface vessel. They have data rates of 10-20 Mbits/s compared to $5 \mathrm{kbits} / \mathrm{s}$ for acoustic, resulting in latencies of microseconds. Optical channels could deliver a week's worth of high-sample-rate $(100 \mathrm{~Hz})$ data on four channels in minutes, thus including both ground motion and pressure gauge information. A year's worth of data might take only $2 \mathrm{hr}$ to upload to end users. A challenge is that although accurate time stamps on data are critical for determining earthquake locations and
Figure 4. Data offload technology concepts using acoustic or optical modems from a variety of platforms. (a) Modem from a glider; (b) autonomous underwater vehicle; and (c) ship of opportunity. The color version of this figure is available only in the electronic edition.

studying seismic structure, Global Positioning System (GPS) timing is not directly available on the seafloor. An optical link would enable the measurement of time drift in an OBS clock to a precision of $\sim 1 \mu$ s relative to a GPS-synchronized time signal relayed by an AUV.

The hitch in optical communication is that currently its maximum range is $\sim 150 \mathrm{~m}$ in seawater, compared to a range of kilometers for acoustic communication. Routine optical data retrieval from a seafloor sensor package requires innovative ideas for new design and may involve several AUVs to relay the signal. We expect that solutions will arise from the marine science community, spurred by the pilot seafloor seismic station envisioned here.

Confidence that acoustic and optical data retrieval methods from the seafloor are practical comes from the variety of communication tools and assets that are already, or soon will be, available. Aside from ever-improving gliders and AUVs, these may include adaptations for early deployments by ships of opportunity. Liquid Robotics is testing a winch system to lower an optical modem with $10 \mathrm{~W}$ of power and 10 Mbits Ethernet to $\sim 150 \mathrm{~m}$ depth from the glider (Fig. $4 \mathrm{a}$ ). AUVs with ranges of several hundreds of nautical miles and the ability to dive to $6000 \mathrm{~m}$ water depth can provide final-leg communication links with satellite systems. An example of this is the REMUS 600, which has an endurance of $70 \mathrm{hr}$ with speeds up to five knots, a range of 286 nautical miles, and an iridium satellite link for communications (Fig. 4b). A simple alternative to an AUVbased optical modem is to use a ship-of-opportunity to visit the OBS site and lower an optical modem on a ship's standard conductivity-temperature-depth wire to within $\sim 100 \mathrm{~m}$ of the station (Fig. 4c). This would allow all of the data to be rapidly retrieved, and the offset of the OBS clock relative to UTC to be accurately measured. 


\section{Instrument suite and logistics of operation and maintenance}

Additional instrumentation requirements were gleaned from the WGLTSS survey (see Section I in the supplemental material). Respondents favored instruments that last far longer than the current $\sim 18$-month maximum recording duration of standard OBSs. Most wanted durations beyond 4 yr. A major reason for this is the desire to wait long enough to obtain highquality earthquake signals from an abundance of azimuths, which is especially vital for studies of anisotropy, and an abundance of large-magnitude earthquakes for studies requiring high-quality body waves. Respondents indicated a desire for a wide frequency range (from 6 min per cycle to $20 \mathrm{~Hz}$ or greater), and for a full range of seismic signal categories-most respondents' interests are in recording body waves, surface waves, normal modes, and ambient noise. Finally, the survey asked about additional instrumentation features and instruments such as the addition of one or more data channels. Nearly half of respondents indicated that they would like a pressure sensor (absolute or differential), about a quarter wanted an accelerometer, and about a quarter opted for a temperature or other environmental sensor.

\section{Timing quality}

Without direct access to GPS data for timekeeping and data tagging, the proposed stations will likely require advancements in autonomous clock performance. Examples include ChipScale Atomic Clocks either operating continuously or in power-cycled mode (e.g., Gardner and Collins, 2012, 2016), which appear to be on the near horizon for undersea use.

\section{Long-term operation and maintenance}

Working group discussions and consultations with the community generated uniform agreement that no pilot seafloor station should be expected to require a ship visit solely for data offload. Ships should be used only for installation, replacement of hardware in the event of failure on multiple seismometers, and for battery replacement. Station design should boost confidence that any problem that does mandate a ship visit be solvable in a very short time-enhancing odds that problems can be addressed by ships of opportunity.

\section{Optimal Locations Based on Scientific Motivation}

The WGLTSS was also tasked with identifying the optimal locations where an initial pilot station might be placed. The metric we used to determine optimal locations was to select regions likeliest to record a large number of body waves with novel ray paths that would be able to probe poorly imaged portions of the Earth's interior, as informed by recent geophysical studies. To do this, we computed the expected number of particular seismic phase arrivals at spots with $1^{\circ}$ spacing in latitude and longitude in the oceans. We computed these statistics for hypothetical seismometer deployments lasting 18 months, $5 \mathrm{yr}$, and 10 yr. Our methodology followed that of Wysession (1996) and figure 5 in the Advancing Global Seismology (2011) report. For each target seismic phase, we examined the appropriate range of epicentral distances that are routinely used for body waves that penetrate deeply into the Earth. We chose reasonable, conservative depth ranges for the events imaged for each phase. We assumed a minimum source magnitude of 6.5 for all phases to mitigate high ocean noise (Webb, 1998). We derived event parameters from the Global Centroid Moment Tensor catalog for earthquakes during the time period 1997-2017 (Dziewonski et al., 1981; Ekström et al., 2012). For simplicity, we assumed seismicity at given locales to be uniformly distributed in time.

It is instructive to note which seismic phases are particularly useful for revealing and assessing different regions of the Earth's interior. Some of the most useful include: (1) $P K P b c$ in conjunction with PKPdf to image the upper inner core; (2) $S m K S$, a group of phases to image the uppermost outer core; (3) $S c P, S c S, S P d K S$, and $S_{d i f}$ to image the lowermost mantle; and (4) SS, $P P$, and receiver functions to probe depth to the Moho layer, the upper-mantle, midmantle, and upper-tolower-mantle transition zone.

The varying geographical richness of diverse phase data recordings can be seen in our resulting maps. Figure 5, for example, shows in pink colors the hypothetical station locations (at $1^{\circ} \times 1^{\circ}$ spacing) where $S c P$ arrivals are likely to be the most abundant, and in blue where we would expect the fewest $S c P$ signals. The three color scales correspond to the three deployment durations. See Section II in the supplemental material for a more comprehensive set of analogous maps produced for different types of seismic phases (Figs. S1-S13). Such maps do not depict regions of the Earth's interior illuminated by the seismic phase in question; nor do they provide information about the arrival directions of phases. Nonetheless, they help guide decisions on station location merit. The selection was further guided by separate, tomographic studies showing where resolution of structures of interest is poor.

It is difficult to justify a lone seafloor station that targets only one region within the Earth's interior. Therefore, we aggregated all of the phase detections for the suite of phases (i.e., Figs. S1-S13) sensitive to each Earth layer at each seafloor location. We took all the phases into account to produce maps showing the absolute number of all possible phases arriving at each hypothetical seismometer location, shown in Figure 6. The regions in pink in this figure are likely to record the largest number of all phases considered together. We then synthesized these data in light of relative noise levels, possibilities of shipof-opportunity traffic, gaps in other OBS projects, and community feedback to refine seafloor pilot station location.

As different seismic phases are observed at different epicentral distances, no single ideal location is possible for the installation of the first seafloor seismic station. A seismologist who is partial to the uppermost outer core structure might choose the 
(a)

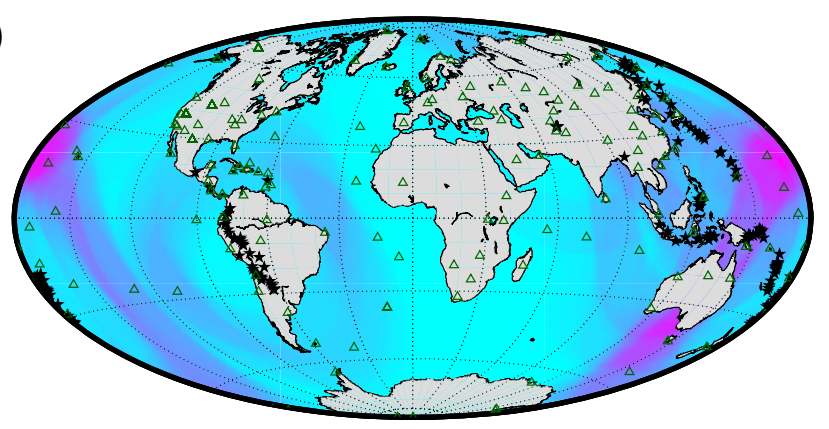

(b)
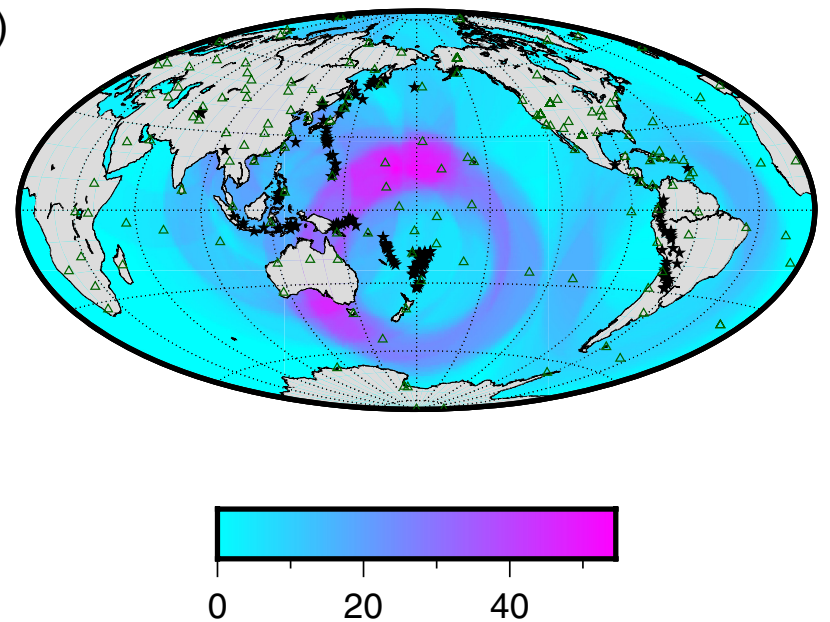

Number of events providing $S c P$ in $10 \mathrm{yr}$

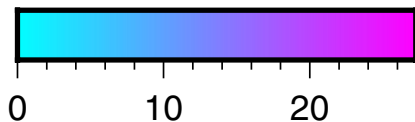

Number of events providing $S c P$ in $5 \mathrm{yr}$

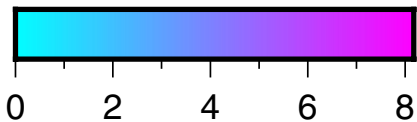

Number of events providing $S c P$ in $1.5 \mathrm{yr}$

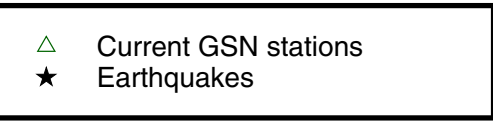

Figure 5. Expected $S C P$ seismic phase arrival detection rates as a function of geographic location. The locations where more SCP arrivals could be detected are shown in pink, and fewer ScP signals detected are shown in blue. The three color scales correspond to three different OBS deployment durations with color indicating how many phases we would expect to record at each possible station location on the seafloor. (a) Africa centered; (b) Pacific centered. Stars, earthquakes within specified time duration with $\mathbf{M}>6.5$; triangles, GSN station locations. The color version of this figure is available only in the electronic edition.

oceans around Africa, whereas one who analyzes receiver functions might wish to record at locations around North America or in the southeastern Pacific Ocean. Crustal thickness is particularly imprecisely estimated in the southern Pacific and Indian oceans, as well as parts of the North Atlantic (e.g., (a)

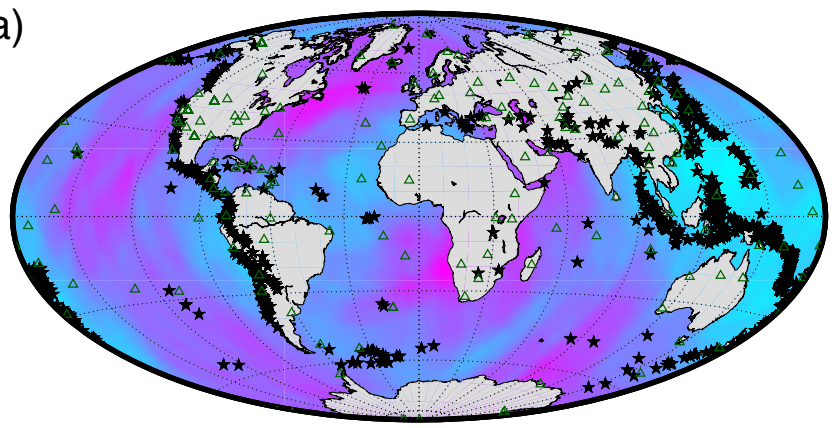

(b)
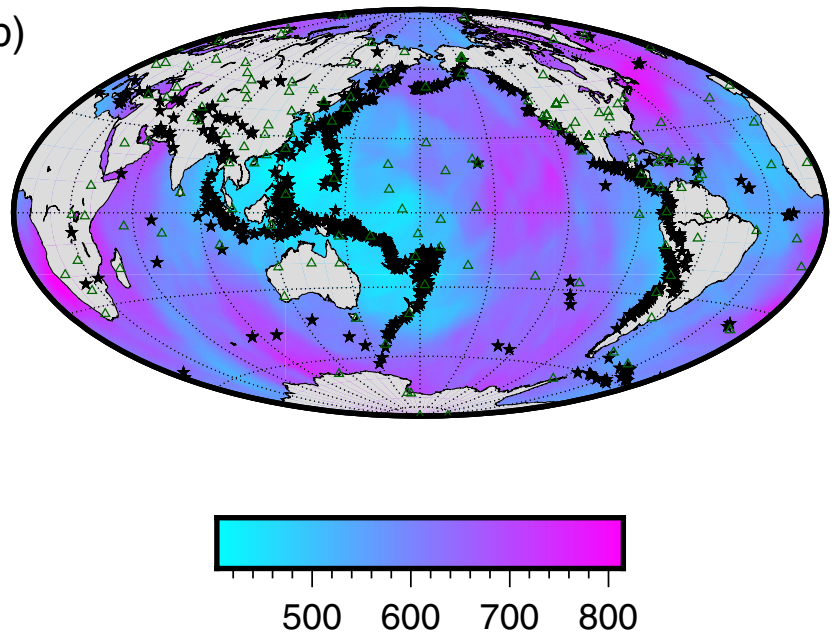

Number of events providing all phases in $10 \mathrm{yr}$

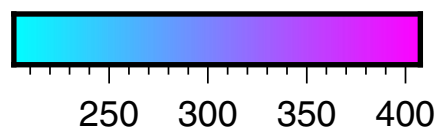

Number of events providing all phases in $5 \mathrm{yr}$

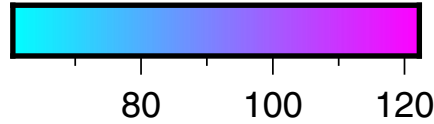

Number of events providing all phases in $1.5 \mathrm{yr}$

\section{$\triangle \quad$ Current GSN stations}

$\star \quad$ Earthquakes

Figure 6. Suite of all the seismic phase types discussed in the Optimal Locations Based on Scientific Motivation section, averaged together to show optimal locations for detection and collection of the largest numbers of all of these phases. The three color scales correspond to three different OBS deployment durations with color indicating how many phases we would expect to record at each possible station location on the seafloor. (a) Africa centered; (b) Pacific centered. Stars, earthquakes within specified time duration with $\mathbf{M}>6.5$; triangles, GSN station locations. The color version of this figure is available only in the electronic edition.

Mooney, 2015). Therefore, a seismologist seeking crustal thickness data guided by detection levels in Figures S1 and S2 might choose a site in the central South Pacific Ocean. For deep core structure, one location that improves upon current coverage is 
a site in the central North Atlantic. The event detection map for $P K P b c-P K P d f$ (Fig. S12) indicates that this region is well placed to see such signals. A central-North Atlantic station in this location would receive incoming $P K P b c$ and $P K P d f$ that transited multiple regions of the inner core, including its portion under the eastern Pacific Ocean and central America. Both those target areas are currently poorly sampled (e.g., Irving and Deuss, 2015) but are important to understanding heterogeneity in inner core body-wave velocities, both isotropic and anisotropic. Also ripe for study from the North Atlantic Ocean and southeastern Pacific Ocean are the ULVZs, which are on the order of 100s of kilometers laterally but just a few tens of kilometers thick, draped on top of the core-mantle boundary.

\section{Conclusions}

Based on information gathered from the community and on discussions of the IRIS GSN Working Group on Long-Term Seafloor Seismographs, the time is right for a pilot study of a long-term, high-quality, broadband seismic station on the seafloor that takes advantage of new technological developments. Through improvements in data quality using burial and in situ battery pack replacement without disturbing the sensor, the pilot project should provide results distinct and different from what can currently be accomplished with standard shorter-term deployments of OBSs, either alone or in array configurations. Data from such a station could be transferred from the seafloor to the seismological community via acoustic or optical telemetry and self-propelled gliders, greatly decreasing the cost of longterm observation. With advances in timekeeping accuracy, deployments lasting four or more years can be envisaged. An analysis of data types needed to obtain the maximum amount of information for studying a variety of global seismology questions (such as oceanic crustal thickness, ULVZ, and core seismic structure) suggest that the optimal location for the pilot site is in the northern Atlantic Ocean or central South Pacific Ocean.

\section{Data and Resources}

Some plots were made using the Generic Mapping Tools v.4.2.1 (www .soest.hawaii.edu/gmt; Wessel and Smith, 1998). Figure 1 was made by Ellen Kappel and Figure 2 by Andy Frassetto. Additional relevant information was obtained from the following websites: National Earthquake Information Center (NEIC, https://earthquake.usgs.gov/earthquakes/), Ocean Networks Canada: Neptune Array (http://www.oceannetworks. ca/observatories), Ocean Observatories Initiative (https://ooi-website. whoi.edu/array/cabled-axial-seamount/), and Pacific Array (http://erindc.eri.u-tokyo.ac.jp/PacificArray/). All websites were last accessed in February 2020. The supplemental material consists of two sections: section I contains the survey questions and percentage breakdowns of respondents' answers to each question; and section II contains maps produced for additional seismic phases.

\section{Acknowledgments}

The authors wish to acknowledge the participants of the 2017 OceanBottom Seismometer (OBS) Symposium, 2017 American Geophysical
Union (AGU) Fall Meeting Special Interest Group (SIG), and 2018 Incorporated Research Institutions for Seismology (IRIS) workshop SIG meetings for their feedback. This study was partially supported by Seismological Facilities for the Advancement of Geoscience (SAGE), which is a major facility fully funded by the National Science Foundation under Cooperative Support Agreement EAR-1851048.

\section{References}

Advancing Global Seismology (2011). A Report to the IRIS Board of Directors by the IRIS GSN Standing Committee, November 2011.

Barnes, C. R., and Neptune Canada Team (2007). Building the world's first regional cabled ocean observatory (NEPTUNE): Realities, challenges and opportunities, OCEANS, doi: 10.1109/OCEANS .2007.4449319.

Bécel, A., M. Laigle, J. Diaz, J.-P. Montagner, and A. Hirn (2011). Earth's free oscillations recorded by free-fall OBS ocean-bottom seismometers at the Lesser Antilles subduction zone, Geophys. Res. Lett. 38, L24305, doi: 10.1029/2011GL049533.

Becker, T., and S. Lebedev (2019). Dynamics of the lithosphere and upper mantle in light of seismic anisotropy, in Mantle Convection and Surface Expression, J. Konter, M. Ballmer, S. Cottaar, and H. Marquardt (Editors), AGU Monograph, doi: 10.31223/osf.io/ kaznt.

Bell, S., Y. Ruan, and D. W. Forsyth (2016). Ridge asymmetry and deep aqueous alteration at the trench observed from Rayleigh wave tomography of the Juan de Fuca plate, J. Geophys. Res. 121, 72987321, doi: 10.1002/2016JB012990.

Berger, J., G. Laske, J. Babcock, and J. Orcutt (2016). An ocean bottom seismic observatory with near real-time telemetry, Earth Space Sci. 3, 68-77, doi: 10.1002/2015EA000137.

Bodmer, M., D. R. Toomey, E. E. Hooft, and B. Schmandt (2018). Buoyant asthenosphere beneath Cascadia influences megathrust segmentation, Geophys. Res. Lett. 45, doi: 10.1029/2018GL078700.

Bowers, D., and N. D. Selby (2009). Forensic seismology and the Comprehensive Nuclear Test Ban Treaty, Annu. Rev. Earth Planet. Sci. 37, 209-236.

Collins, J. A., F. L. Vernon, J. A. Orcutt, and R. A. Stephen (2002). Upper Mantle structure beneath the Hawaiian swell: Constraints from the ocean seismic network pilot experiment, Geophys. Res. Lett. 29, no. 11, 1522, doi: 10.1029/2001GL013302.

Collins, J. A., F. L. Vernon, J. A. Orcutt, R. A. Stephen, K. R. Peal, F. B. Wooding, F. N. Spiess, and J. A. Hildebrand (2001). Broadband seismology in the oceans: Lessons from the Ocean Seismic Network Pilot Experiment, Geophys. Res. Lett. 28, no. 1, 49-52, doi: 10.1029/2000GL011638.

Crawford, W. C. (2006). A second look at low-frequency marine vertical seismometer data quality at the OSN-1 site off Hawaii for seafloor, buried and borehole emplacements, Bull. Seismol. Soc. Am. 96, no. 5, 1952-1960, doi: 10.1785/0120050234.

Crawford, W. C., and S. C. Webb (2000). Identifying and removing tilt noise from low frequency $(0.1 \mathrm{~Hz})$ seafloor vertical seismic data, Bull. Seismol. Soc. Am. 90, 952-963.

Creasy, N., A. Pisconti, M. D. Long, C. Thomas, and J. Wookey (2019). Constraining lowermost mantle anisotropy with body waves: A synthetic modelling study, Geophys. J. Int. 217, no. 2, 766-783.

Deschamps, A., Y. Hello, P. Charvis, T. Frontera, and C. Gojak (2008). A real time seismological station at $2500 \mathrm{~m}$ depth in front of 
Toulon, New Trends for Environmental Monitoring Using Passive Systems, doi: 10.1109/PASSIVE.2008.4786998.

Detrick, R. S., R. S. White, and G. M. Purdy (1993). Crustal structure of North Atlantic fracture zones, Rev. Geophys. 31, 439-458.

Dolenc, D., B. Romanowicz, D. Stakes, and P. McGill (2005). Observations of infragravity waves at the Monterey ocean bottom broadband station (MOBB), Geochem. Geophys. Geosys. 6, no. Q09002, doi: 10.1029/2005GC000988.

Dolenc, D., B. Romanowicz, R. Uhrhammer, P. McGill, D. Neuhauser, and D. Stakes (2007). Identifying and removing noise from the Monterey ocean bottom broadband seismic station (MOBB) data, Geochem. Geophys. Geosys. 8, no. Q02005, doi: 10.1029/ 2006GC001403.

Doran, A. K., and G. Laske (2016). Infragravity waves and horizontal seafloor compliance, J. Geophys. Res. 121, 260-278, doi: 10.1002/ $2015 J B 012511$.

Duennebier, F. K., and G. H. Sutton (2007). Why bury ocean bottom seismometers? Geochem. Geophys. Geosys. 8, no. Q02010, doi: 10.1029/2006GC001428.

Dunn, R. (2015). Crust and lithospheric structure-Seismic structure of mid-ocean ridges, in Treatise of Geophysics, Second Ed., B. Romanowicz and A. Dziewonski (Editors), Vol. 1, Chapter 1.13, 419-451.

Dziewonski, A. M., T.-A. Chou, and J. H. Woodhouse (1981). Determination of earthquake source parameters from waveform data for studies of global and regional seismicity, J. Geophys. Res. 86, 2825-2852, doi: 10.1029/JB086iB04p02825.

Ekström, G., M. Nettles, and A. M. Dziewonski (2012). The global CMT project 2004-2010: Centroid-moment tensors for 13,017 earthquakes, Phys. Earth Planet. In. 200/201, 1-9, doi: 10.1016/ j.pepi.2012.04.002.

Forsyth, D., A. Dziewonski, and B. Romanowicz (1995). Scientific objectives and required instrumentation, in Broadband Seismology in the Oceans: Towards a Five Year Plan, M. Purdy (Editor), Proceedings of the Ocean Seismic Network Workshop, Joint Oceanographic Institutions, Washington, D.C., 8-18.

Forsyth, D. W., S. C. Webb, L. R. M. Dorman, and Y. Shen (1998). Phase velocities of Rayleigh waves in the MELT experiment on the East Pacific Rise, Science 280, no. 5367, 1235-1238, doi: 10.1126/ science.280.5367.1235.

Frye, D., L. Freitag, R. Detrick, J. Collins, J. Delaney, D. Kelley, A. LaBonte, and K. Brown (2006). An acoustically linked mooredbuoy observatory, Eos Trans. AGU 87, no. 22, 213, doi: 10.1029/2006EO220002.

Future Geophysical Facilities Required to Address Grand Challenges in the Earth Sciences (2015). A Community Report to the National Science Foundation, September 2015, available at https://www.iris .edu/hq/files/publications/other_workshops/docs/futures_report .pdf (last accessed February 2020).

Gardner, A. T., and J. A. Collins (2012). Advancements in high-performance timing for long term underwater experiments: A comparison of chip scale atomic clocks to traditional microprocessorcompensated crystal oscillators, 2012 OCEANS, 14-19 October 2012, 1-8, doi: 10.1109/OCEANS.2012.6404847.

Gardner, A. T., and J. A. Collins (2016). A second look at Chip Scale Atomic Clocks for long term precision timing: Four years in the field, OCEANS 2016 MTS/IEEE Monterey, Monterey, California, 2016, 1-9, doi: 10.1109/OCEANS.2016.7761268.

Grevemeyer, I., N. W. Hayman, C. Peirce, M. Schwardt, H. J. A. Van Avendonk, A. Dannowski, and C. Papenberg (2018). Episodic magmatism and serpentinized mantle exhumation at an ultraslow-spreading centre, Nature Geosci. 11, 444-448, doi: 10.1038/ s41561-018-0124-6.

Irving, J. C. E., and A. Deuss (2011). Stratified anisotropic structure at the top of Earth's inner core: A normal mode study, Phys. Earth Planet. In. 186, 59-69, doi: 10.1016/j.pepi.2011.03.003.

Irving, J. C. E., and A. Deuss (2015). Regional seismic variations in the inner core under the North Pacific, Geophys. J. Int. 203, 2189-2199, doi: 10.1093/gji/ggv435.

Kanamori, H. (2014). The diversity of large earthquakes and its implications for hazard mitigation, Annu. Rev. Earth Planet. Sci. 42, 7 26, doi: 10.1146/annurev-earth-060313-055034.

Kaneda, Y., K. Kawaguchi, E. Arak, H. Matsumoto, T. Nakamura, S. Kamiya, K. Ariyoshi, T. Hori, T. Baba, and N. Takahashi (2015). Development and application of an advanced ocean floor network system for megathrust earthquakes and tsunamis, in Seafloor Observatories, P. Favali, L. Beranzoli, and A. De Santis (Editors), Springer Praxis Books, 643-662, doi: 10.1007/978-3-642-11374-1_25.

Kawaguchi, K., S. Kaneko, T. Nishida, and T. Komine (2015). Construction of the DONET real-time seafloor observatory for earthquakes and tsunami monitoring, in Seafloor Observatories, P. Favali, L. Beranzoli, and A. De Santis (Editors), Springer Praxis Books, 211-228, doi: 10.1007/978-3-642-11374-1_10.

Kelley, D. S., J. R. Delaney, and S. K. Juniper (2014). Establishing a new era of submarine volcanic observatories: Cabling axial seamount and the endeavour segment of the Juan de Fuca Ridge, Mar. Geol. 352, 426-450.

Korenaga, J. (2011). Velocity-depth ambiguity and the seismic structure of large igneous provinces: A case study from the Ontong Java Plateau, Geophys. J. Int. 185, 1022-1036, doi: 10.1111/j.1365246X.2011.04999.x.

Laske, G., J. Phipps Morgan, J. A. Orcutt, G. R. Foulger, and D. M. Jurdy (2007). The Hawaiian SWELL pilot experiment: Evidence for lithosphere rejuvenation from ocean bottom surface wave data, in Plates, Plumes and Planetary Processes, G. R. Foulger and D. M. Jurdy (Editors), Special Paper 430, Geological Society of America, Boulder, Colorado, 209-233.

Lay, T. (Editor) (2009). Seismological grand challenges in understanding Earth's dynamic systems, Report to the National Science Foundation, IRIS Consortium, 76 pp., available at http://www.iris .edu/hq/lrsps/seis_plan_final.pdf (last accessed February 2020).

Lay, T. (2015). Deep Earth structure; lower mantle and D, in Treatise on Geophysics, B. Romanowicz and A. M. Dziewonski (Editors), Vol. 1, Chapter 1.22, 684-723.

Lin, P.-Y. P., J. B. Gaherty, G. Jin, J. A. Collins, D. Lizarralde, R. L. Evans, and G. Hirth (2016). High-resolution seismic constraints on flow dynamics in the oceanic asthenosphere, Nature 535, 538-541, doi: 10.1038/nature18012.

Long, M., and T. W. Becker (2010). Mantle dynamics and seismic anisotropy, Earth Planet. Sci. Lett. 297, 341-354, doi: 10.1016/ j.epsl.2010.06.036.

Montagner, J. P. and Y. Lancelot (Editors) (1995). Multidisciplinary Observatories on the Deep Seafloor, Report of the International 
Ocean Network Workshop held at Marseille, France, 01/11-01/13/95, Institut National des Sciences de l'Univers/Centre National de la Recherche Scientifique, Ocean Drilling Project-France.

Mooney, W. D. (2015). Crust and lithospheric structure-Global crustal structure, in Seismology and the Structure of the Earth, B. Romanowicz and A. Dziewonski (Editors), Treatise on Geophysics, Vol. 1, Elsevier, Amsterdam, The Netherlands, 361-417, doi: 10.1016/B978-044452748-6.00011-0.

Nishida, K. (2013). Earth's background free oscillations, Annu. Rev. Earth Planet. Sci. 41, 719-740.

National Science Foundation (NSF) External Review of the GSN (2015). GSN Review Committee Report, available at https://www.iris.edu/hq /files/programs/gsn/documents/GSN_Review_Final_Submitted _20150715.pdf (last accessed February 2020).

Pachhai, S., H. Tkalčić, and G. Masters (2016). Estimation of splitting functions from Earth's normal mode spectra using the neighbourhood algorithm, Geophys. J. Int. 204, no. 1, 111-126, doi: 10.1093/gji/ggv414.

Park, J., T.-R. A. Song, J. Tromp, E. Okal, S. Stein, G. Roult, E. Clevede, G. Laske, H. Kanamori, P. Davis, et al. (2005). Earth's free oscillations excited by the 26 December 2004 Sumatra-Andaman earthquake, Science 308, 1139-1144.

Purdy, G. M., and A. M. Dziewonski (1988). Proceedings of a Workshop on Broad-band Downhole Seismometers in the Deep Ocean, Joint Oceanographic Institutions, Inc. and the JOI U.S. Science Advisory Committee, Washington, D.C., 105 pp.

Romanowicz, B., and R. Wenk (2017). Anisotropy in the deep Earth, Phys. Earth Planet. In. 269, 58-90.

Romanowicz, B., P. McGill, D. Neuhauser, and D. Dolenc (2009). Acquiring real time data from the Broadband Ocean Bottom Seismic Observatory at Monterey Bay (MOBB), Seismol. Res. Lett. 80, no. 2, 197-202, doi: 10.1785/gssrl.80.2.197.

Romanowicz, B., D. Stakes, R. Uhrhammer, P. McGill, D. Neuhauser, T. Ramirez, and D. Dolenc (2003). The MOBB experiment: A prototype permanent offshore ocean bottom broadband station, Eos Trans. AGU 84, 325-332.

Satake, K. (2015). Tsunamis, in Treatise on Geophysics, G. Beroza and H. Kanamori (Editors), Vol. 4, Chapter 4.19, 477-504.

Souriau, A. (2015). Deep earth structure: The Earth's cores, in Treatise on Geophysics, B. Romanowicz and A. M. Dziewonski (Editors), Vol. 1, Chapter 1.19, 656-693.

Suetsugu, D., and H. Shiobara (2014). Broadband ocean-bottom seismology, Annu. Rev. Earth Planet. Sci. 42, 27-43, doi: 10.1146/ annurev-earth-060313-054818.

Sukhovich, A., S. Bonnieux, Y. Hello, J.-O. Irisson, F. Simons, and G. Nolet (2015). Seismic monitoring in the oceans by autonomous floats, Nat. Comm. 6, Article Number 8027, doi: 10.1038/ ncomms 9027.
Sutherland, F. H., F. L. Vernon, J. A. Orcutt, J. A. Collins, and R. A. Stephen (2004). Results from OSNPE: Improved teleseismic earthquake detection at the seafloor, Bull. Seismol. Soc. Am. 94, no. 5, 1868-1878, doi: 10.1785/012003088.

Suyehiro, K., J. P. Montagner, R. A. Stephen, E. Araki, T. Kanazawa, J. Orcutt, B. Romanowicz, S. Sacks, and M. Shinohara (2006). Ocean seismic observatories, Oceanography 19, 104-109.

Tauzin, B., E. Debayle, and G. Wittlinger (2010). Seismic evidence for a global low-velocity layer within the Earth's upper mantle, Nature Geosci. 3, 718-721, doi: 10.1038/ngeo969.

Tilmann, F., B. M. Howe, and R. Butler (2017). Commercial underwater cable systems could reduce disaster impact, Eos Trans. AGU 98, doi: 10.1029/2017EO069575.

Tkalčić, H. (2015). Complex inner core of the Earth: The last frontier of global seismology, Rev. Geophys. 53, 59-94, doi: 10.1002/ 2014RG000469.

Van Avendonk, H. J. A., J. K. Davis, J. L. Harding, and L. A. Lawver (2017). Decrease in oceanic crustal thickness since the breakup of Pangaea, Nature Geosci. 10, 58-61, doi: 10.1038/ngeo2849.

Waszek, L., N. C. Schmerr, and M. D. Ballmer (2018). Global observations of reflectors in the mid-mantle with implications for mantle structure and dynamics, Nat. Comm. 9, 385, doi: 10.1038/ s41467-017-02709-4.

Webb, S. C. (1998). Broadband seismology and noise under the ocean, Rev. Geophys. 36, no. 1, 105-142, doi: 10.1029/97RG02287.

Webb, S. C., and W. C. Crawford (1999). Long-period seafloor seismology and deformation under ocean waves, Bull. Seismol. Soc. Am. 89, 1535-1542.

Wei, S. S., and P. M. Shearer (2017). A sporadic low-velocity layer atop the $410 \mathrm{~km}$ discontinuity beneath the Pacific Ocean, J. Geophys. Res. 122, 5144-5159, doi: 10.1002/2017JB014100.

Wessel, P., and W. H. F. Smith (1998). New, improved version of the Generic Mapping Tools released, Eos Trans. AGU 79, 579.

Working Group on Long-Term Seafloor Seismographs (WGLTSS) (2020). Available at https://www.iris.edu/hq/about_iris/governance/wgltss (last accessed February 2020).

Wysession, M. (1996). How well do we utilize global seismicity? Bull. Seismol. Soc. Am. 86, 1207-1219.

Yu, S., and E. J. Garnero (2018). Ultralow velocity zone locations: A global assessment, Geochem. Geophys. Geosys. 19, no. 2, 396-414, doi: 10.1002/2017GC007281.

Yu, W. C., J. Su, T. R. A. Song, H. H. Huang, L. Mozziconacci, and B. S. Huang (2017). The inner core hemispheric boundary near $180^{\circ} \mathrm{W}$, Phys. Earth Planet. In. 272, 1-16. 